\title{
Fertility status of the rubber growing tracts in agro- ecological units of Southern Kerala
}

\author{
Rekha V. R. Nair and Usha Mathew
}

Article Chronicle : Received: 19.10.2018;

Revised : 20.11.2018;

Accepted :

28.11.2018

Key Words : Rubber, Agro ecological units, Fertility, Nutrient classification
ABSTRACT : Natural rubber cultivation has crossed 100 years in its traditional belt in Kerala and it is in third or fourth cycle of replanting. Repeated cycles of past one century led to decline in soil health. Appraisal of current status of soil fertility parameters is of immense importance. Hence, the study was undertaken to adopt strategies for sustaining soil health and productivity. Geo referenced soil samples from $0-30 \mathrm{~cm}$ and $30-60 \mathrm{~cm}$ depth from different mature rubber plantations in the agro-ecological units of $1,8,9,12$ and 14 in southern Kerala were collected. Accordingly sixty five samples were analyzed for different parameters such as $\mathrm{pH}$, E.C, oxidisable organic carbon, available phosphorus, potassium, calcium, magnesium, sulphur, iron, copper, zinc, manganese and boron. Soil samples were classified into different categories based on soil test values. All soil samples were acidic and majority were under extreme acidic condition. Available nitrogen, phosphorus and potassium status were in medium range. Severe deficiency of calcium and magnesium were noticed in the soil samples. Among micronutrients iron and manganese were in optimum range and boron and zinc were extremely deficient. All these factors can contribute to loss of productivity of soil. Hence ideal methodology suggested for soil health is discriminatory fertilizer application (DFA) by soil and leaf sampling and suggesting fertilizer recommendations.

HOW TO CITE THIS ARTICLE : Nair, Rekha V.R. and Mathew, Usha (2018). Fertility status of the rubber growing tracts in agro- ecological units of Southern Kerala. Asian J. Environ. Sci., 13(1\&2): 26-32, DOI: 10.15740/HAS/AJES/13.1and2/26-32.
Author for correspondence :

\section{Rekha V. R. Nair}

Department of

Soil Science and

Agricultural Chemistry,

College of Agriculture,

Vellayani,

Thiruvanathapuram,

(Kerala) India

Email : rekhavrnair@

gmail.com.

See end of the article for

Coopted authors' 